\title{
BACKSCATTERED ELECTRON IMAGING ANALYSIS OF MORTAR CONTAINING FLY ASH AND CALCIUM CARBONATE NANOPARTICLES
}

\author{
"HUASHAN YANG, YUJUN CHE \\ School of Materials and Architecture Engineering, Guizhou Normal University, Guiyang 550025, China \\ "E-mail: 201510003@gznu.edu.cn
}

Submitted October 3, 2019; accepted December 9, 2019

\begin{abstract}
Keywords: Cement, Calcium carbonate nanoparticles, Hydration products, Pore structure
To solve the problem of the reduction in strength due to the high-volume of fly ash (FA) in cement, this research investigates the influences of calcium carbonate nanoparticles (NCS) on the microstructure and strength of mortar containing $40 \% \mathrm{FA}$ at the early and later ages. Two NCs (NC1 and NC2) were added at rates of $2 \%$ as a partial replacement for the binder, respectively. The characteristics of large capillary pores, the dense and porous areas, the constituent phase fractions, the hydration degree of the cement, the porosity, and the pore structure of mortar containing FA and NCs were analysed by backscattered electron imaging analysis (BSI). Mortar containing FA without NCs was used as a control mortar (PCFA). The results show that mortar containing $2 \%$ NCs exhibited about $13.6 \%$ and $6.7 \%$ higher compressive strengths than that of the PCFA at 3 and 180 days, respectively. Furthermore, the incorporation of the NCs decreases the porous hardened cement paste $(H C P)$ areas, but increases the dense HCP. Besides, the results reveal that the hydration degree, the pore volume, and the larger capillary pores of the mortar containing the NCs is about $9.7 \%, 15.5 \%$, and $30.5 \%$ lower than that of the PCFA at 3 days, respectively. The results of the BSI analysis also indicate that the NCs could reduce the porosity, the large capillary pores, and the porous HCP area of the mortar, creating a denser microstructure, resulting in a higher compressive strength in the later ages.
\end{abstract}

\section{INTRODUCTION}

Given developing sustainable building materials, the replacement of cement with supplementary cementitious materials (SCMs) such as fly ash, granulated blast furnace slag, and silica fume has been widely recognised as a viable solution [1]. The use of such SCMs leads to a significant reduction in $\mathrm{CO}_{2}$ emissions [2-4]. It is reported that the FA replacement in cement improves the mechanical properties as well as the durability of the concrete [5]. However, the amount of FA is limited to $15-25 \%$ of the total cementitious materials [6]. The high level of FA used in concrete may result in low earlyage strength and long setting time, both of which slow construction.

To overcome the deficiencies caused by the high-volume replacement of FA to achieve a desirable strength, the incorporation of nanoparticles is an effective method [7-10]. Thus, the use of nanoparticles in construction materials is of increasing interest. The use of nanoparticles can, not only enhance the strength $[11,12]$ and durability [13], but also introduce new functionality, such as being photocatalytic [14]. However, the majority of the studies so far have focused on nano-silicas [15-18]. As the cost of nano-silicas is relatively high, it is necessary to look for an alternative nanoparticle for the application of a mortar with FA.
It is reported that NCs alter the cement hydration by at least three different mechanisms [19-22]: (1) heterogeneous nucleation, (2) dilution effects, and (3) filler effects. Thus, NCs are considered to be the right candidate for inclusion in a mortar with FA. However, NCs have not been widely investigated in mortars with FA. Most studies have focused on its effectiveness in improving the early-age properties. Accordingly, its long-term properties are often overlooked. Therefore, more investigation, such as the pozzolanic activity of the fly ash in the presence of NCs at later ages and the development of a pore structure of the mortar with FA, still needs to be undertaken to further understand the mechanisms underlying the influence of the NCs.

Parameters, such as pore diameters, porosity, and pore size distribution, are critical with regards to the mechanical properties and durability of cementitious materials. Mercury intrusion porosimetry (MIP) analysis is widely used to evaluate the total porosity and size distributions of the pores in cement pastes and concretes. However, MIP analysis does not provide the correct measurements of the sizes of the pores that exist in the systems [23]. Therefore, the application of BSI for the investigation of the microstructure of cement and concrete has attracted considerable interest [24-29]. The intensity of the BSI signal is a function of the average atomic number of the local area of the specimen [29]. 
Areas with high average atomic numbers generate strong signals, resulting in a bright contrast in the BSI. For instance, the hydration products have lower average atomic numbers than the unhydrated clinker, and, thus, a sharp contrast is obtained between the hydration products and the unhydrated clinkers. Therefore, unhydrated clinkers, hydration products, and pores in an original BSI image can be quantitatively evaluated by the procedures of the image analysis [30]. Scrivener et al. reported that, compared to fracture surfaces that reveal a path of weakness, flat polished sections of the specimens could be prepared to be representative. They found that the measurement of 10 images at a magnification of $400 \times$ was sufficient to give a standard error of about $0.6 \%$ in the cement pastes [31]. Studies have also shown that the amount of unhydrated clinker, hydration products, and pores measured by the BSI analysis corresponds well with independent measurements of hydration [29, 31]. Diamond S. et al. determined the pore size distribution of capillary pores in a hardened paste by SEM image analysis [32]. They found that image analysis appears to provide a reasonably accurate assessment of both the capillary pores and the air voids. However, few investigations on the quantitative relationship between the porosity, hydration degree, and compressive strength of the specimens have been found. Furthermore, the HCP in concrete, which contains dense areas and porous areas, can be examined by BSI analysis [33]. The dense areas showed a high local concentration of the residual unhydrated clinker, the porous areas being comparatively few [34].

The objective of this study is to investigate the influences of NCs on the microstructure and strength of a mortar containing FA at early and later ages by BSI analysis. The capillary pores and characteristics of the dense and porous areas in the mortar were observed by the low-magnification backscattered electron images. The constituent phase fractions, hydration degree of the

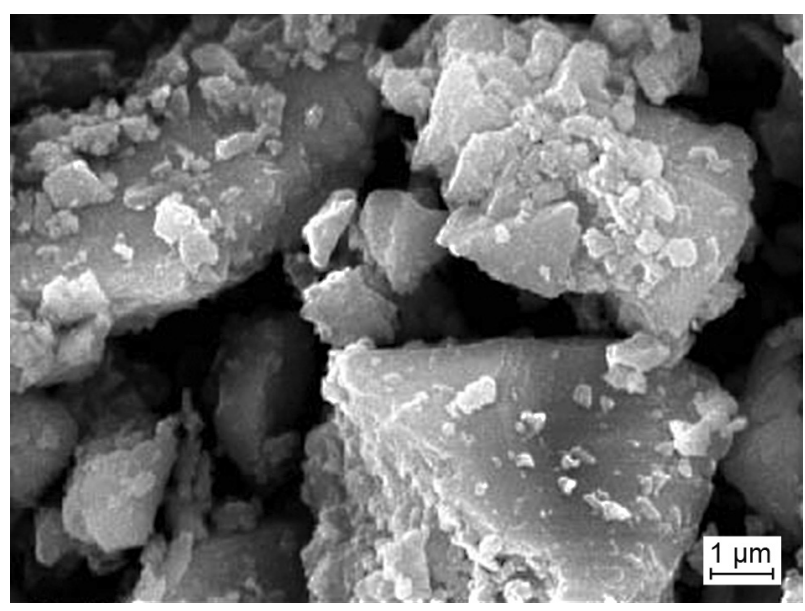

a) clinker, and pore structure were calculated by the highmagnification backscattered electron images. The relationship of the porosity, hydration degree, and compressive strength at 3,28 , and 180 days was also discussed.

\section{EXPERIMENTAL}

\section{Materials}

All the mixtures were produced with Portland cement (PC) (P.I 42.5), fly ash (FA), ISO standard sand, mixing water, a high range water reducer admixture (HRWRA), and NCs. Two NCs, named NC1 and NC2, obtained from different sources were incorporated separately into the mixtures to evaluate their effects on the compressive strength, hydration products, constituent phase fractions, and pore structure of the mortar with the FA. The SEM images of NC1 and NC2 are shown in Figures 1a, b, respectively, illustrating the different particle sizes and morphology of the two NCs. Table 1

Table 1. The chemical composition of the PC and FA and the mineralogical composition of the PC.

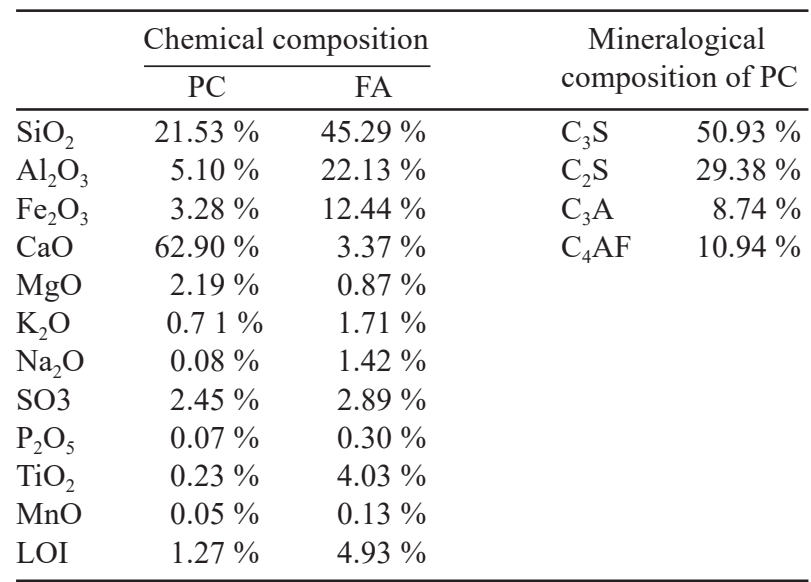

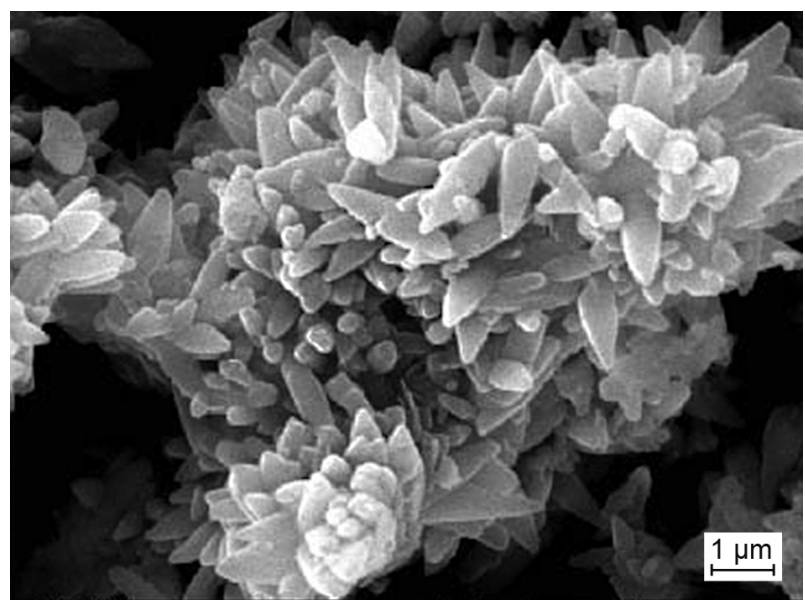

b)

Figure 1. The SEM images of the NCs. a) NC1, b) NC2. 
presents the chemical and mineralogical composition (Bogue) of the PC, as well as the chemical composition of the FA. The Bogue potential composition of the $\mathrm{PC}$ is $\mathrm{C}_{3} \mathrm{~S}=50.93 ; \mathrm{C}_{2} \mathrm{~S}=29.38 ; \mathrm{C}_{3} \mathrm{~A}=8.74 ; \mathrm{C}_{4} \mathrm{AF}=10.94 \%$.

\section{Methods}

The mixtures were designed using different NCs. The mixture proportions are shown in Table 2. In the mixtures, the water to binder ratio and sand to binder ratio remained constant. The specimens prepared for the experiment contained $2 \% \mathrm{NCs}$ by weight, except for the control specimens (PCFA). The NC dosages are added as a percentage of the binder.

Due to the large specific surface area, the NCs are more susceptible to agglomeration by van der Waals, electrostatic, and magnetic forces. These phenomena in cementitious materials have been widely reported $[35,36]$. From a practical standpoint, the effective use of NCs relies on the ability to achieve a uniform and stable dispersions [37]. Thus, all the mixing water was mixed with HRWRA, firstly, whose dosages are $0.5 \%$ of the binder. The solid ingredients were mixed by a standard mortar mixer at a low speed for 30 seconds. Then, the water with HRWRA was added into the dry ingredients, and mixing was continued for 30 seconds at a low speed in the mortar mixer. After that, high-speed mixing was continued for three minutes. After completion of the mixing and casting, all the specimens were kept inside prism moulds $(40 \times 40 \times 160 \mathrm{~mm})$ for 24 hours at $95 \pm 5 \%$ RH (relative humidity), $20 \pm 2{ }^{\circ} \mathrm{C}$. After 24 hours in the moulds, the specimens were demoulded and cured in saturated lime water at $20 \pm 2{ }^{\circ} \mathrm{C}$ until the testing ages.

The mortars with FA and NCs were characterised in terms of the compressive strength and the BSI image analysis. The compressive strength testing involved six specimens at the ages of 3, 28, and 180 days. For the BSI image analysis, slices of about $10 \mathrm{~mm}$ in thickness were cut from the specimens at the prescribed ages. They were dried by successive immersions in acetone and ethanol to remove most of the water and then placed in an oven for 24 hours at $50{ }^{\circ} \mathrm{C}$. After that, the slices were finely polished with $\mathrm{SiC}$ paper.

The specimens were examined using an SEM equipped with a backscatter detector. Low-magnification BSI images were used to characterise the dense and porous areas in the mortar and were compared with the results from the PCFA. High-magnification BSI images, at a magnification of $1000 \times$, were used to calculate the constituent phase fractions in the mortar.

Ten fields in each specimen were randomly chosen to calculate the constituent phase fractions in the mortar. Figure 2a shows a typical high-magnification BSI image of the PCFA at 3 days. It can be seen that its scale length is $10 \mu \mathrm{m}$, which consists of 100 pixels. Thus, the size of one pixel is about $0.1 \mu \mathrm{m}$. A cluster analysis method, a way to separate groups of objects, was used to segment

Table 2. The mix proportion of the specimens

\begin{tabular}{llllcccc}
\hline Specimens & $\begin{array}{l}\text { PC } \\
(\%)\end{array}$ & $\begin{array}{c}\text { FA } \\
(\%)\end{array}$ & $\begin{array}{c}\text { NC1 } \\
(\%)\end{array}$ & $\begin{array}{c}\text { NC2 } \\
(\%)\end{array}$ & $\begin{array}{c}\text { HRWRA } \\
(\%)\end{array}$ & $\begin{array}{c}\text { Water to binder } \\
\text { ratio }\end{array}$ & $\begin{array}{c}\text { Sand to binder } \\
\text { ratio }\end{array}$ \\
\hline PCFA & 60 & 40 & - & - & 0.5 & 0.4 & $1: 3$ \\
NC1-2 & 58.8 & 39.2 & 2 & - & 0.5 & 0.4 & $1: 3$ \\
NC2-2 & 58.8 & 39.2 & - & 2 & 0.5 & 0.4 & $1: 3$ \\
\hline
\end{tabular}

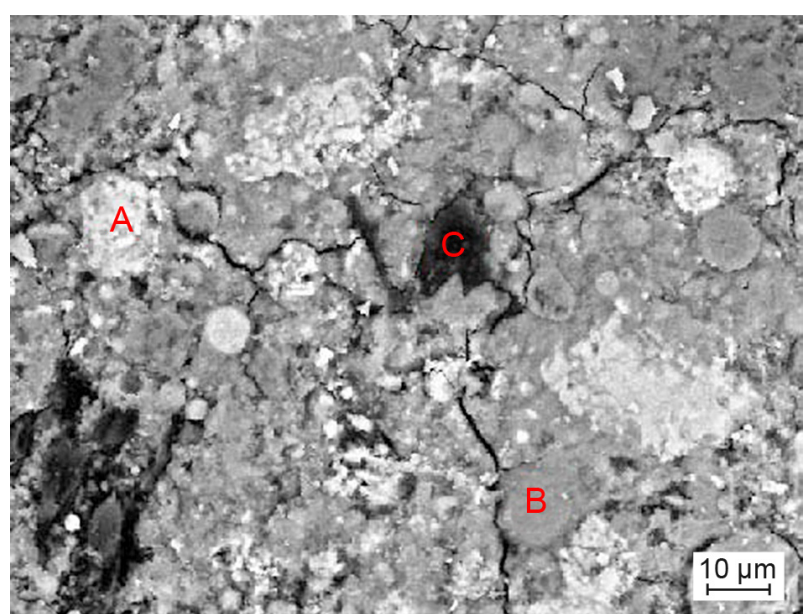

a)

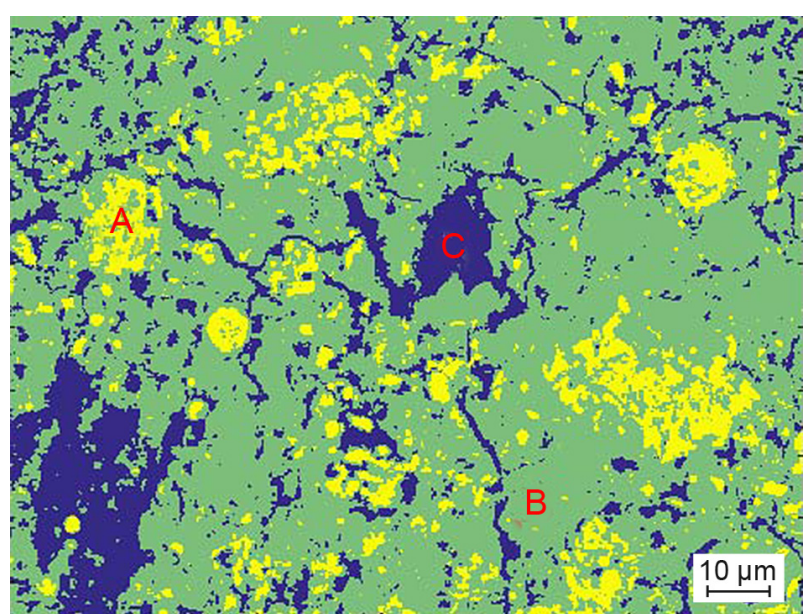

b)

Figure 2. A typical high-magnification BSI image of the PCFA at 3 days a) and the results of the cluster analysis of the BSI image b), where $\mathrm{A}$ - the unhydrated clinker; $\mathrm{B}$ - the hydration products and fly ash; $\mathrm{C}$ - the pores. 
the unhydrated clinker, hydration products, and pores in this image. K-means clustering finds partitions so that objects within each cluster are as close to each other as possible. Thus, the pixels for unhydrated clinker, for the hydration products, and the pores were tallied to obtain the area fractions of the three phases. The results are shown in Figure 2b. Granulometry determines the size distribution of the pores in an image, which estimates the intensity surface area distribution of the pores as a function of size. This method likens the pores to sands whose sizes can be determined by sifting them through screens of increasing size and collecting what remains after each pass. Thus, the pore size distribution of the specimens at the different curing ages can be determined. The degree of hydration of the cement $(\alpha)$ was calculated by Equation 1 [30].

$$
\alpha=1-U H_{\mathrm{i}} / U H_{0},
$$

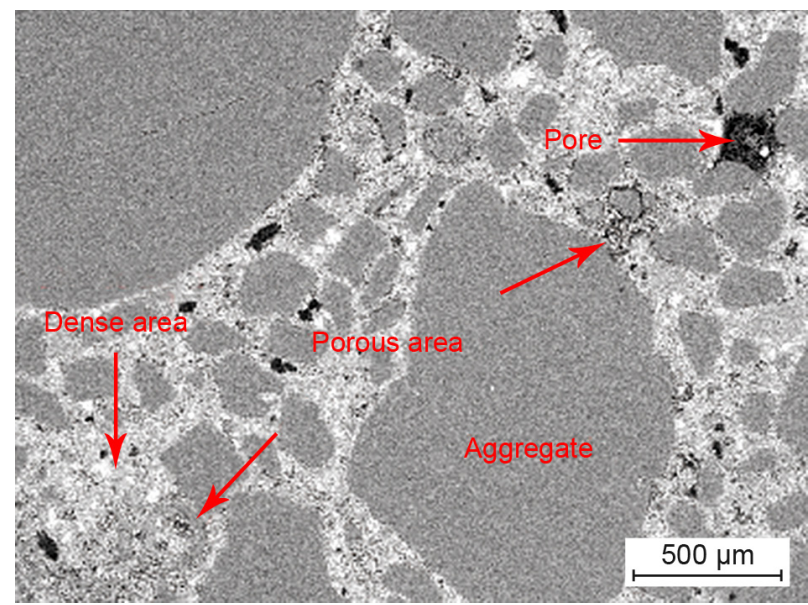

a) PCFA where $U H_{\mathrm{i}}$ : the area fraction of the unhydrated clinker at the age of $t_{i} ; U H_{0}$ : the initial area fraction of the unhydrated clinker.

\section{RESULTS}

The characteristics of the dense and porous areas in the mortar

Figure 3 a presents a low-magnification BSI image showing the characteristic dense and porous areas in the PCFA at 3 days. More than a dozen uniformly grey sand grains of various sizes are visible in this figure. The space between the sand grains is filled with HCP. The bright portions are the residual unhydrated clinker. The dark portions are the pores. Two varieties of HCP can be observed in this figure, easily distinguished from each other. One variety appears to be nonporous at this

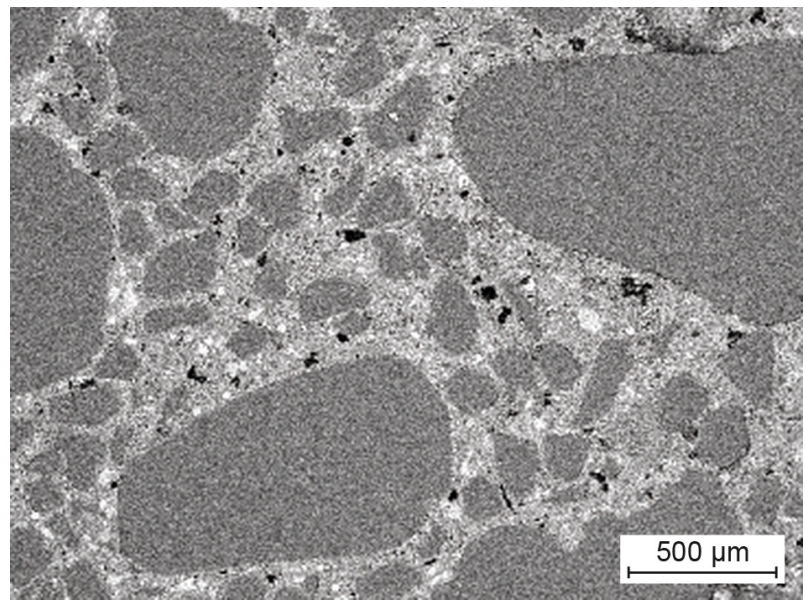

b) $\mathrm{NC} 1-2$

Figure 3. The low-magnification BSI image showing the characteristics of the dense and porous areas in the mortar at 3 days: a) PCFA; b) NC1-2.

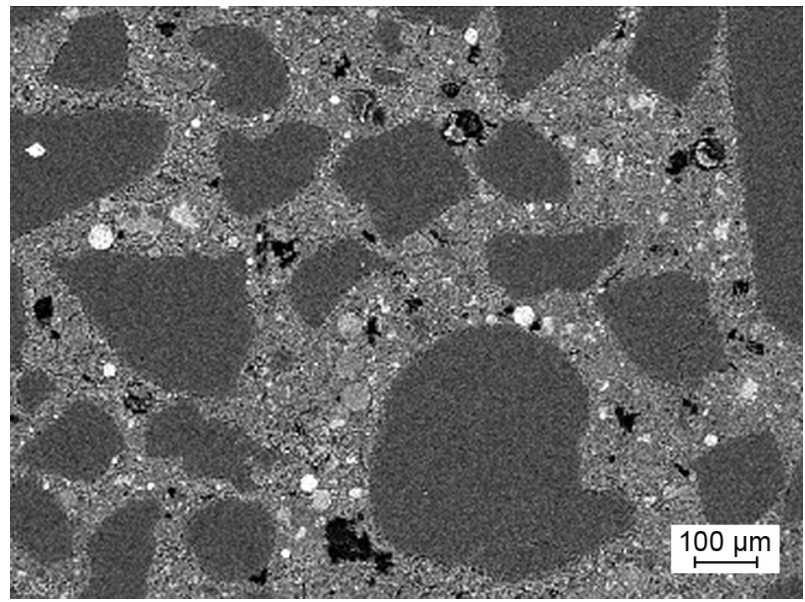

a) PCFA

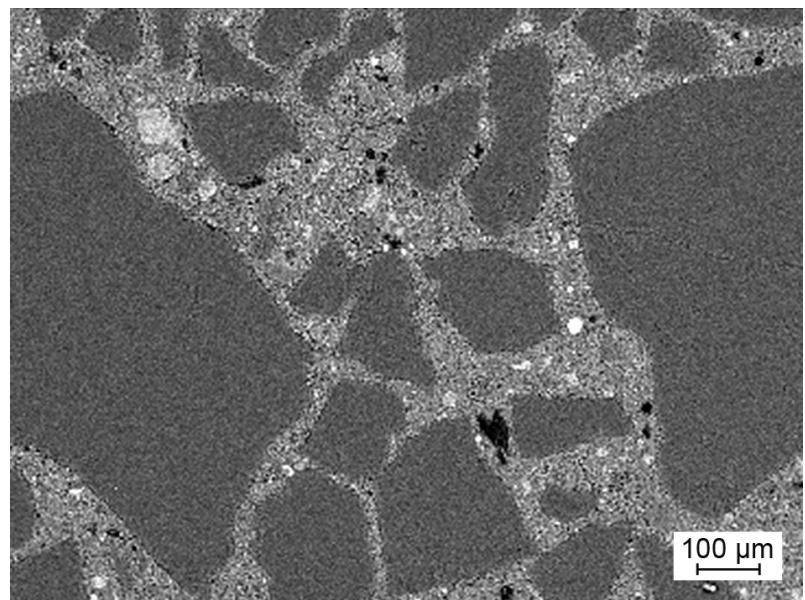

b) NC1-2

Figure 4. The low-magnification BSI image showing the characteristic dense and porous areas in the mortar at 28 days: a) PCFA; b) $\mathrm{NC} 1-2$. 
low magnification, which is the dominant form of HCP. A representative area illustrating this variety of $\mathrm{HCP}$ is marked "Dense area". The other appears to be much more visibly porous. A representative area illustrating this variety of HCP is marked "Porous area."

Figure $3 \mathrm{~b}$ shows areas of brightness, pores, a dense $\mathrm{HCP}$, and a porous HCP similar to those found in the PCFA discussed previously. There is a difference in that the proportion of the large pores and the porous HCP areas is considerably smaller, and that of the dense HCP correspondingly higher, than in the PCFA. The reduction in the pore size indicates that the NCs refine the large capillary pores of the fly ash mortar at 3 days. The large capillary pores become disconnected and hence result in a decrease in the permeability of the mortar. The decrease in the porous $\mathrm{HCP}$ areas indicates that the NCs encourage the formation of a denser area $\mathrm{C}-\mathrm{S}-\mathrm{H}$ at 3 days. Thus, the use of NCs could increase in the microstructure of the mortar.

Figures $4 \mathrm{a}$ and $\mathrm{b}$ present the low-magnification BSI image showing the characteristic dense and porous areas in the PCFA and NC1-2 at 28 days, respectively. It appears similar to that of Figure 3, with distinct areas of pores, dense HCP, and porous HCP all present. Compared to Figure $4 \mathrm{a}$, Figure $4 \mathrm{~b}$ considers the exhibited smaller pores and porous HCP areas, which indicates that the incorporation of the NCs refines the pore size of the mortar and optimises the microstructure of the hardened cement paste at 28 days.

\section{Constituent phase fractions in the mortar containing FA and $\mathrm{NC}$}

Figure 5a, b, c show the volume fractions of the constituent phases in the specimens at 3,28, and 180 days, respectively. The volume fractions of the unhydrated clinker and pores of all the specimens decreased with time. Still, the reduction in the volume fraction of the unhydrated clinker in NC1-2 and NC2-2 was not so conspicuous as in the PCFA. The volume of the hydration products detected by the BSI image increased with time, in concert with the decrease in the volume of the unhydrated clinker and pores.

The volume of the hydration products of the mortar containing NCs is almost the same in that of the PCFA at 3 days, and the volume of the unhydrated clinker is higher than that of the PCFA, but the pore volume is lower than that of the PCFA. The volume of the unhydrated clinker of the NC1-2 and NC2-2 is $17.1 \%$ and $4.7 \%$ higher than that of the PCFA, respectively. The pore volume of NC1-2 and NC2-2 is $13.8 \%$ and $17.2 \%$ lower than that of the PCFA, respectively. A similar phenomenon can be observed at 28 days. However, the pore volume in NC1-2 and NC2-2 is smaller than that of the PCFA at 180 days, whereas the pore volume of NC1-2 and NC2-2 is $2.1 \%$ and $26.8 \%$ lower than that of the PCFA, respectively. The decrease in porosity can be attributed to the filler effects of the NCs, which effectively fill the pores, leading to a denser microstructure of the mortar containing NCs compared to that of the PCFA.

Figure $6 \mathrm{a}, \mathrm{b}, \mathrm{c}$ show the degrees of the cement hydration, which were calculated with Equation 1 using the volume fractions of the unhydrated clinker measured by the BSI image analysis. It was found that the hydration degree of all the specimens increases with time. After 28 days, the hydration degrees of the PCFA still increase with time, but the hydration degree of NC1-2 and NC2-2 increase very slowly. With the ongoing cement hydration, the cement grains are consumed, and the hydration products which are deposited onto the cement grain surface grow thicker [38]. As shown in Figure 7, the dense hydration products fill all the

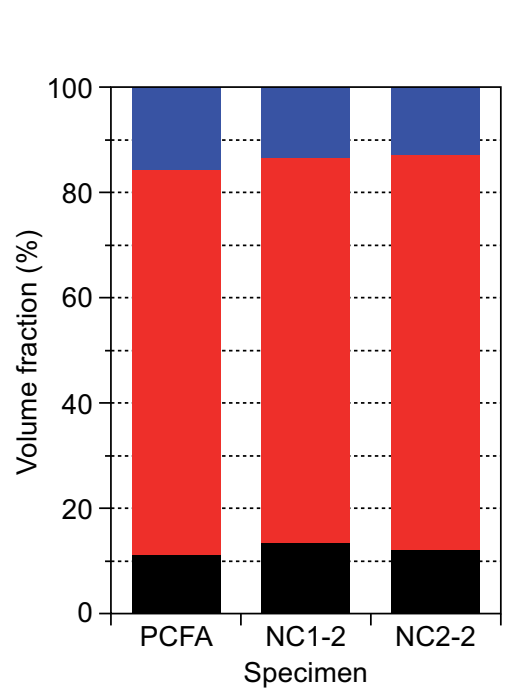

a) 3 days

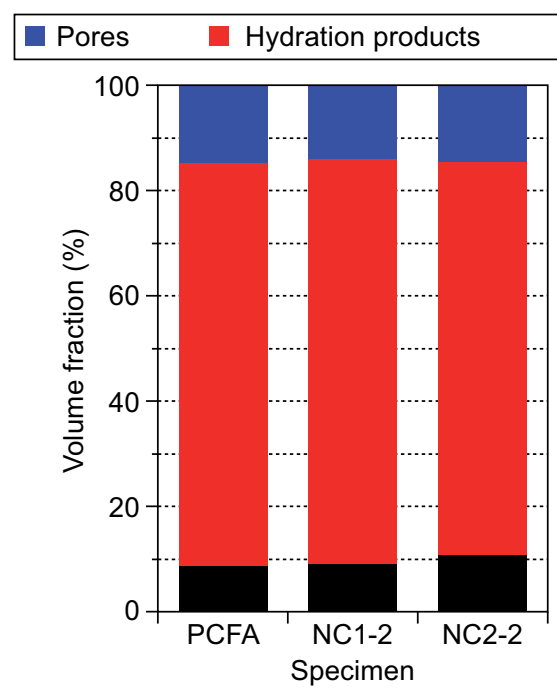

b) 28 days

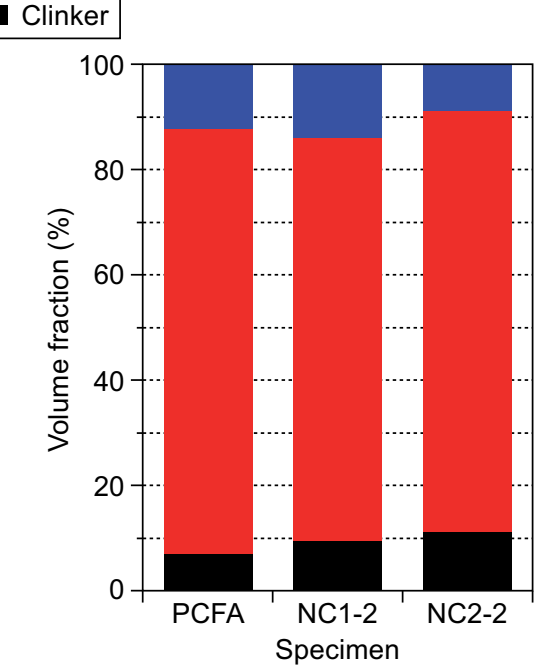

c) 180 days

Figure 5. The volume fractions of the constituent phases in the specimens: a) hydration for 3 days; b) hydration for 28 days; c) hydration for 180 days. 
space around the residual clinker grains, resulting in a smaller hydration space for the clinker grains. The lack of available space for the hydration products limited the accelerated hydration induced by the presence of the NCs [39]. It also can be seen from Figure 6 that the hydration degree of the mortar containing NCs is lower than that of the PCFA at the 3 ages. The hydration degree of NC1-2 and NC2-2 is $14.0 \%$ and $5.3 \%$ lower than that of the PCFA at 3 days, which indicates that the accelerating effects of the NCs on the cement cannot be observed at the early ages. A similar trend can be also observed at 28 and 180 days.

\section{The pore structure of mortar with the FA and NCs}

The effects of the NCs on the pore size distribution of mortar at 3, 28, and 180 days are shown in Figure $8 \mathrm{a}, \mathrm{b}, \mathrm{c}$, respectively. We classify the pores from 0.1 to $0.5 \mu \mathrm{m}$ as small capillary pores, from 0.5 to $1.0 \mu \mathrm{m}$ as medium capillary pores and $>1.0 \mu \mathrm{m}$ as large capillary pores.

As can be seen from Figure 8, the small capillary pores increased with time in all the samples; correspondingly, the large capillary pores decreased with time. At the age of 180 days, the medium capillary pores reduced significantly in all the specimens, which can be attributed to the hydration of the cement and the pozzolanic reaction of the fly ash in the mortar. Coarser pores are gradually refined as a result of an increase in the gel volume from the cement hydration, which fills the water-filled gel pores and reduces the capillary pores.

It can also be observed that both the small capillary pores and the medium capillary pores of the mortar containing NCs are higher than that of the PCFA at all ages. Concerning NC1-2, the small capillary pores are $16.8 \%, 9.8 \%$, and $15.2 \%$ higher than that of the PCFA at 3,28 , and 180 days, respectively. Correspondingly, the larger capillary pores are $39.6 \%, 44.5 \%$, and $62.4 \%$ lower than that of the PCFA at 3,28 and 180 days,

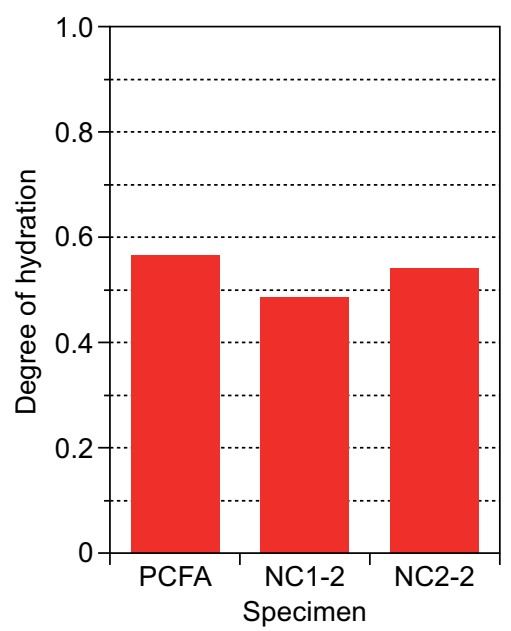

a) 3 days

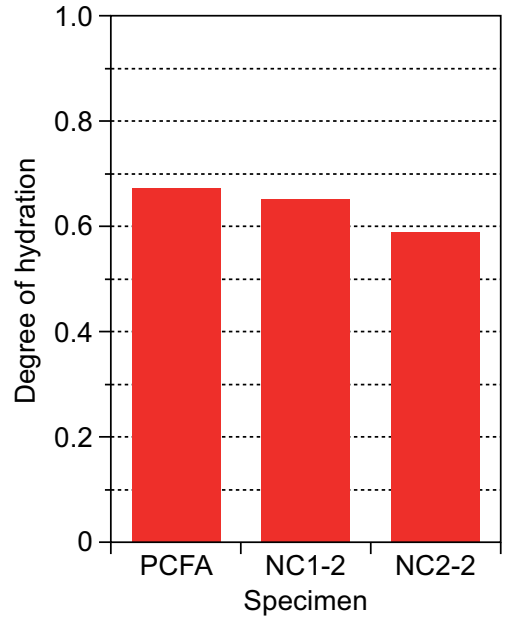

b) 28 days

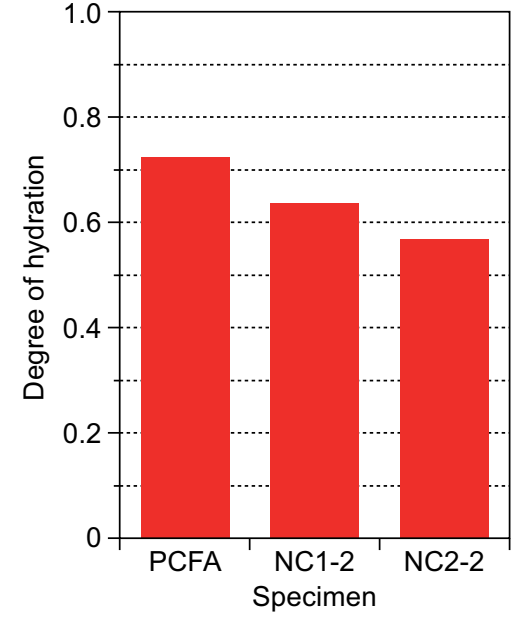

c) 180 days

Figure 6. The degree of hydration for: a) 3 days; b) 28 days; c) 180 days.

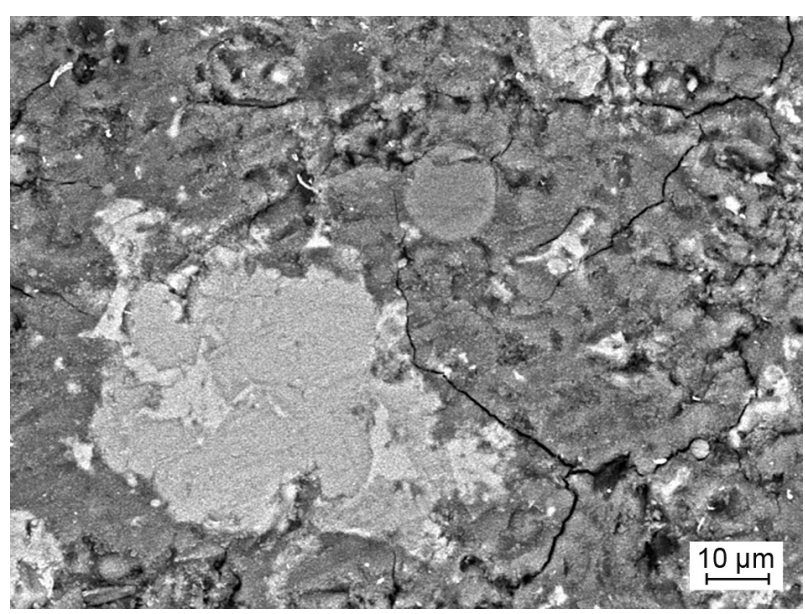

a) 28 days

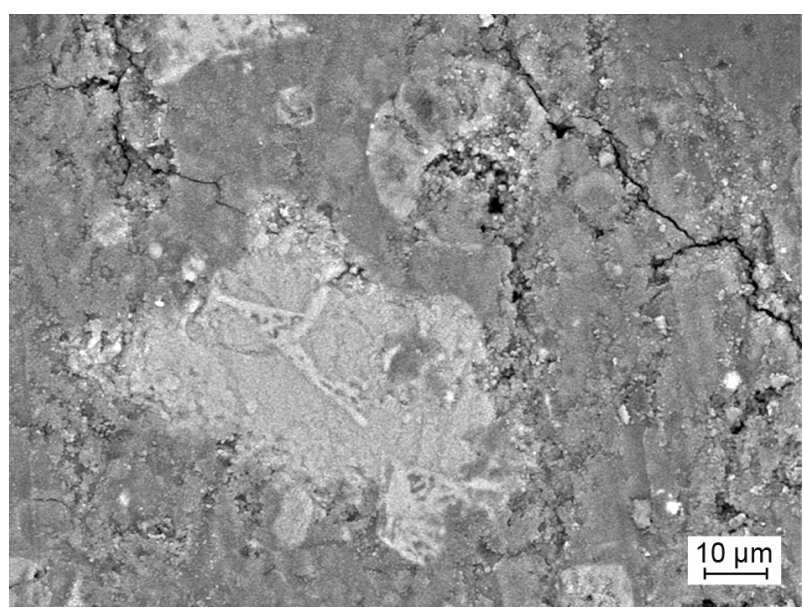

b) 180 days

Figure 7. The unhydrated clinker in NC2-2: a) hydration for 28 days; b) hydration for 180 days. 
respectively. Concerning NC2-2, the small capillary pores are $3.1 \%, 4.9 \%$, and $5.6 \%$ higher than that of the PCFA at 3,28, and 180 days, respectively. Correspondingly, the larger capillary pores are $21.3 \%, 40.5 \%$, and $49.9 \%$ lower than that of the PCFA at 3, 28, and 180 days, respectively. In this case, the use of NCs leads to a more compact mortar with a significant reduction in the large capillary pores, indicating the presence of the NCs is

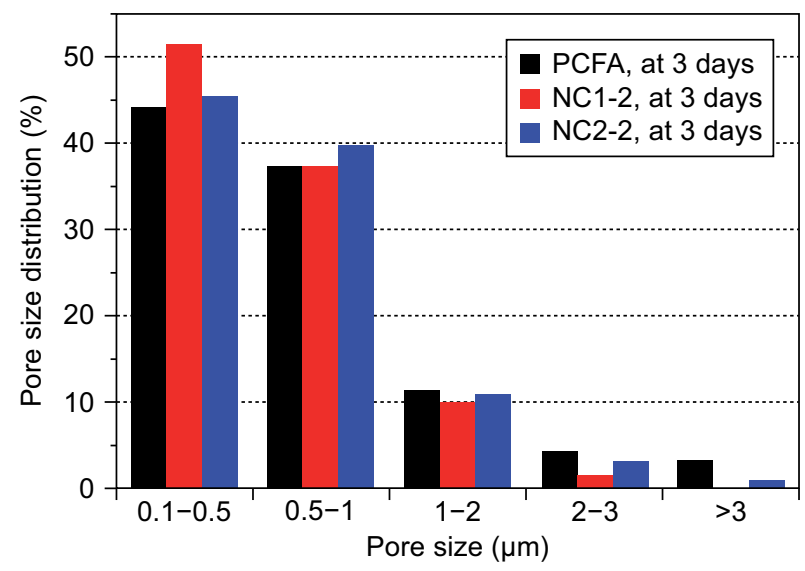

a)

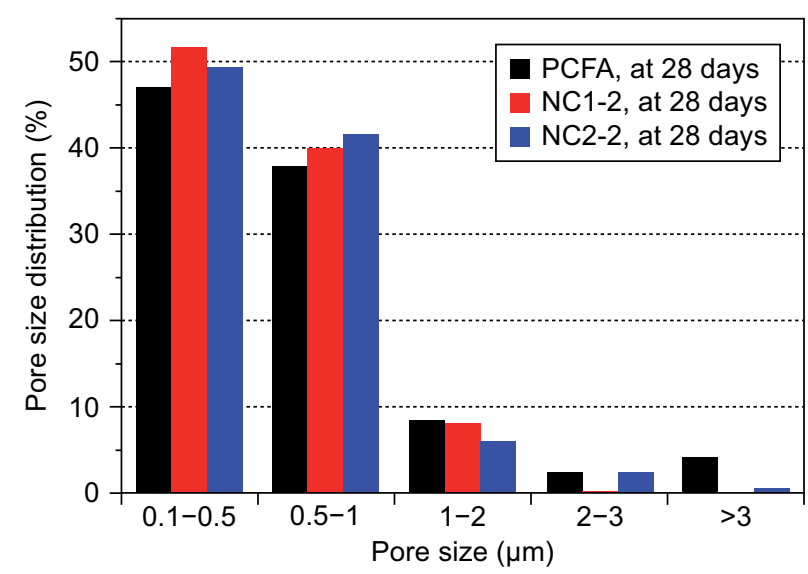

b)

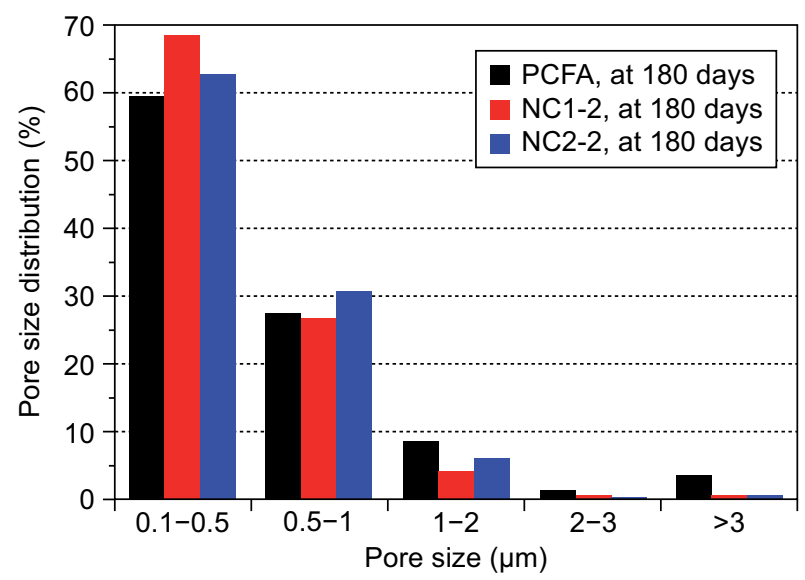

c)

Figure 8. The pore size distribution. a) hydration for 3 days; b) hydration for 28 days; c) hydration for 180 days. advantageous in the pore modification. It is noted that the $\mathrm{NCs}$, due to the filler effects, have a significant influence in decreasing the large capillary pores of the mortar [40]. It is reported that the permeability of the concrete is affected mainly by the large and medium capillary pores [41]. Thus, the incorporation of NCs improves the resistance of permeability resulting in the reduction of the deterioration of the mortar containing FA.

\section{DISCUSSION}

The compressive strength, hydration degree, and porosity of all the mortars at 3 days are compared in Figure 9. As seen from Figure 9, the compressive strength of NC2-2 at 3 days surpassed the other mortars, but it was closely followed by NC1-2. The PCFA has the lowest compressive strength. The mortar containing NCs exhibited about $13.6 \%$ higher compressive strengths than that of the PCFA at 3 days, which indicates the effectiveness of the NCs in compensating the low compressive strength at the early age of the mortar containing FA. Shaikh [40] and Kawashima [42] also found that the addition of the NCs is an effective means to improve the mechanical properties of the cementitious materials at the early-ages.

The most interesting aspects of the current experimental study are the constituent phase fractions, hydration degree, and porosity results. The volume of the clinker of the mortar containing the NCs is about $10.9 \%$ higher than that of the PCFA at 3 days, and the hydration degree of the mortar containing the NCs is about $9.7 \%$ lower than that of the PCFA. These results indicate that the accelerating effects of the NCs on the cement is not observed at the early-ages. The pore volume of the mortar containing the NCs is about $15.5 \%$ lower than that of the PCFA at 3 days, indicating that the NCs refines the pore size of the mortar at the early-ages. Furthermore, as discussed formerly, the NCs modified the microstructure of the HCP even at the early-ages, which led to a decrease in the large capillary pores and porous areas. Besides, the results of the pore structure analysis revealed that the small capillary pores of the mortar containing NCs are about $10.0 \%$ higher than that of the PCFA at 3 days. Correspondingly, the larger capillary pores are about $30.5 \%$ lower than that of the PCFA at 3 days. Thus, the higher early-age compressive strength of the mortar containing the NCs than that of the PCFA can be attributed to the filler effects of the NCs at the early-ages.

The compressive strength of the PCFA is slightly higher than that of NC1-2, but lower than that of NC2-2 at 28 days. However, with the development of the hydration, the mortar containing the NCs outperformed the PCFA in terms of the compressive strength at 180 days. The mortar containing the NCs exhibited about $6.7 \%$ higher compressive strengths than that of the PCFA 


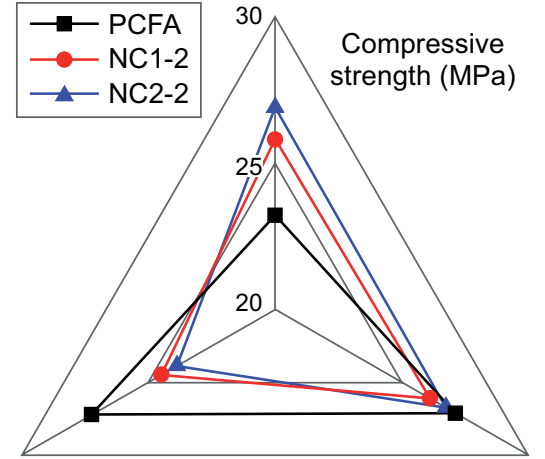

Porosity (\%)
Hydration degree (\%)

a) 3 days

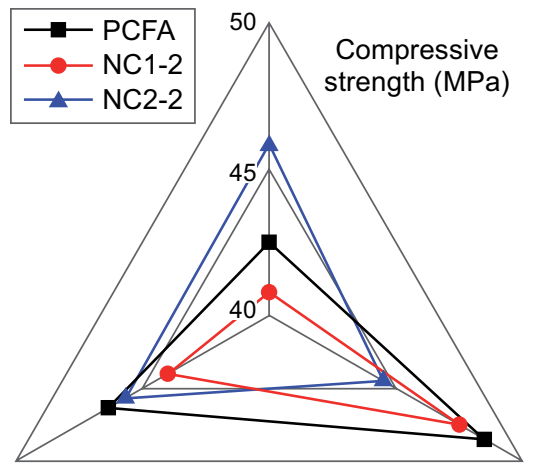

Hydration degree (\%)

b) 28 days

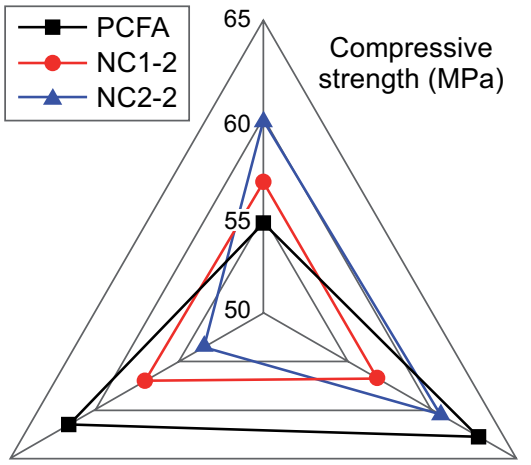

Hydration degree (\%)

c) 180 days

Figure 9. The compressive strength, hydration degree, and porosity of the mortar: a) hydration for 3 days; b) hydration for 28 days; c) hydration for 180 days.

at 180 days, which revealed that the NCs successfully modified the mortar with the FA in the long term. Similar to the age of 3 days, the enhancement in the compressive strength of the mortar containing the NCs at 28 and 180 days is related to the refinement of the pores and the modification of the $\mathrm{C}-\mathrm{S}-\mathrm{H}$ bonds. The pore volume and the larger capillary pores of the mortar containing the NCs is about $14.5 \%$ and $56.2 \%$ lower than that of the PCFA at 180 days, respectively. Correspondingly, the small capillary pores of the mortar containing the NCs is about $10.4 \%$ higher than that of the PCFA at 180 days. As a consequence, the microstructure of the mortar was improved. This finding corroborates the ideas of Shaikh [43], who suggested that the NCs filled the pores and increased the density of cementitious materials. Besides, the mortar containing the NCs decreased the porosity, but did not increase the hydration degree of the cement at 28 and 180 days. The hydration degree of the mortar containing the NCs is about $17.1 \%$ lower than that of the PCFA at 180 days. This is because the mortar containing the NCs has a more compact microstructure than that of the PCFA at the later ages, and the hydration products do not have enough space to grow, which slows down the hydration of the clinker.

\section{CONCLUSIONS}

The influences of the NCs on the microstructure and strength of the mortar containing FA at the early and later ages were investigated in this study. The main conclusions can be summarised as follows:

- The addition of $2 \%$ NCs improved both the earlyage and later-age compressive strength of the mortar containing the FA, which can be attributed to the filler effects of the NCs and the modification of the microstructure of the mortar containing the FA.

- The NCs modified the microstructure of the HCP both at the early-age and later-age, which leads to the decrease of the large capillary pores and porous areas.
- The addition of NCs increases the small capillary pore diameter, but causes the reduction of the sizeable capillary pore diameter of the mortar containing the FA. Thus, the presence of the NCs in the mortar containing the FA is advantageous in the pore modification both at the early-age and later-age.

- The test results of the porosity, the hydration degree of the cement, and the compressive strength confirm that $2 \%$ of the NCs decreased the capillary porosity, which improved the compressive strength of the mortar containing the FA at 28 and 180 days.

- In general, the reduction of the large capillary pores and porous HCP area is the main reason for the higher strength of the mortar containing the NCs in the later ages.

\section{Acknowledgements}

We would like to thank the funds from the National Natural Science Foundation of China (grant number 51669004) and the Science and Technology Programme of Guizhou Province (grant number [2017]7346).

\section{REFERENCES}

1. Hemalatha M.S., Santhanam M. (2018): Characterizing supplementary cementing materials in blended mortars, Construction and Building Materials, 191, 440-459. doi: 10.1016/j.conbuildmat.2018.09.208

2. Armengaud J., Cyr M., Casaux-Ginestet G., Husson B. (2018): Durability of dry-mix shotcrete using supplementary cementitious materials, Construction and Building Materials, 190, 1-12. doi: 10.1016/j.conbuildmat.2018.09. 107

3. Yang K.-H., Jung Y.-B., Cho M.-S., Tae S.-H. (2015): Effect of supplementary cementitious materials on reduction of $\mathrm{CO}_{2}$ emissions from concrete, Journal of Cleaner Production, 103, 774-783. doi: 10.1016/j.jclepro.2014.03.018 
4. Vargas J., Halog A. (2015): Effective carbon emission reductions from using upgraded fly ash in the cement industry, Journal of Cleaner Production, 103, 948-959. doi: 10.1016/j.jclepro.2015.04.136

5. Uysal M., Akyuncu V. (2012): Durability performance of concrete incorporating Class $\mathrm{F}$ and Class $\mathrm{C}$ fly ashes, Construction and Building Materials, 34, 170-178. doi: 10.1016/j.conbuildmat.2012.02.075

6. Hemalatha T., Mapa M., George N., Sasmal S. (2016): Physico-chemical and mechanical characterization of high volume fly ash incorporated and engineered cement system towards developing greener cement, Journal of Cleaner Production, 125, 268-281. doi: 10.1016/j.jclepro.2016.03. 118

7. Niewiadomski P., Hola J., Cwirzen A. (2018): Study on properties of self-compacting concrete modified with nanoparticles, Archives of Civil and Mechanical Engineering, 18, 877-886. doi: 10.1016/j.acme.2018.01.006

8. Varghese L., Rao V., Parameswaran L. (2018): Improvement of early-age strength of high-volume siliceous fly-ash concretewithnanosilica-Areview,Advancesin CivilEngineering Materials, 7, 599-615. doi: 10.1520/ACEM20180065

9. Meng T., Yu Y., Wang Z., (2017): Effect of nano- $\mathrm{CaCO}_{3}$ slurry on the mechanical properties and micro-structure of concrete with and without fly ash, Composites Part B. Engineering, 117, 124-129. doi: 10.1016/j.compositesb. 2017.02.030

10. Li W.G., Huang Z.Y., Cao F.L., Sun Z.H., Shah S.P. (2015): Effects of nano-silica and nano-limestone on flowability and mechanical properties of ultra-high-performance concrete matrix, Construction and Building Materials, 95, 366-374. doi: 10.1016/j.conbuildmat.2015.05.137

11. Jo B.W., Kim C.H., Tae G.H., Park J.B. (2007): Characteristics of cement mortar with nano- $\mathrm{SiO}_{2}$ particles, Construction and Building Materials, 21, 1351-1355. doi: 10.1016/j.conbuildmat.2005.12.020

12. Yang H., Che Y. (2018): Effects of nano- $\mathrm{CaCO}_{3} /$ lime-stone composite particles on the hydration products and pore structure of cementitious materials, Advances in Materials Science and Engineering, 2018, 1-8. doi: 10.1155/2018/ 5732352

13. Du H.J., Du S.H., Liu X.M. (2014): Durability performances of concrete with nano-silica, Construction and Building Materials, 73, 705-712. doi: 10.1016/j.conbuildmat.2014. 10.014

14. Yousefi A., Allahverdi A., Hejazi P. (2013): Effective dispersion of nano- $\mathrm{TiO}_{2}$ powder for enhancement of photocatalytic properties in cement mixes, Construction and Building Materials, 41, 224-230. doi: 10.1016/j. conbuildmat.2012.11.057

15. Silvestre J., Silvestre N., de Brito J. (2016): Review on concrete nanotechnology, European Journal of Environmental and Civil Engineering, 20, 455-485. doi: 10.1080/ 19648189.2015.1042070

16. Aggarwal P., Singh R.P., Aggarwal Y. (2015): Use of nano-silica in cement based materials-A review, Cogent Engineering, 2, 1-11. doi: 10.1080/23311916.2015.1078018

17. Singh L.P., Karade S.R., Bhattacharyya S.K., Yousuf M.M., Ahalawat S. (2013): Beneficial role of nanosilica in cement based materials - A review, Construction and Building Materials, 47, 1069-1077. doi: 10.1016/j. conbuildmat.2013.05.052
18. Said A.M., Zeidan M.S., Bassuoni M.T., Tian Y. (2012): Properties of concrete incorporating nano-silica, Construction and Building Materials, 36, 838-844. doi: 10.1016/j. conbuildmat.2012.06.044

19. Uthaman S., Vishwakarma V., George R.P., Ramachandran D., Kumari K., Preetha, Premila R. M., Rajaraman R., Mudali U.K., Amarendra G. (2018): Enhancement of strength and durability of fly ash concrete in seawater environments: Synergistic effect of nanoparticles, Construction and Building Materials, 187, 448-459. doi: 10.1016/j. conbuildmat.2018.07.214

20. Nejad F.M., Tolouei M., Nazari H., Naderan A. (2018): Effects of calcium carbonate nanoparticles and fly ash on mechanical and permeability properties of concrete, Advances in Civil Engineering Materials, 7, 651-668. doi: 10.1520/ACEM20180066

21. Jayapalan A.R., Lee B.Y., Kurtis K.E. (2013): Can nanotechnology be 'green'? Comparing efficacy of nano and microparticles in cementitious materials, Cement and Concrete Composites, 36, 16-24. doi: 10.1016/j.cemconcomp. 2012.11.002

22. Lawrence P., Cyr M., Ringot E. (2003): Mineral admixtures in mortars: effect of inert materials on short-term hydration, Cement and concrete research, 33, 1939-1947. doi: 10.1016/S0008-8846(03)00183-2

23. Diamond S. (2000): Mercury porosimetry - An inappropriate method for the measurement of pore size distributions in cement-based materials, Cement and concrete research, 30, 1517-1525. doi: 10.1016/S0008-8846(00)00370-7

24. Li Y., Guo W., Li H. (2016): Quantitative analysis on ground blast furnace slag behavior in hardened cement pastes based on backscattered electron imaging and image analysis technology, Construction and Building Materials, 110, 48-53. doi: 10.1016/j.conbuildmat.2016.02.015

25. Hu C.L., Ma H.Y. (2016): Statistical analysis of backscattered electron image of hydrated cement paste, Advances in Cement Research, 28, 469-474. doi: 10.1680/jadcr. 16.00002

26. Deschner F., Munch B., Winnefeld F., Lothenbach B. (2013): Quantification of fly ash in hydrated, blended Portland cement pastes by backscattered electron imaging, Journal of Microscopy, 251, 188-204. doi: 10.1111/jmi.12061

27. Feng S.X., Liu X.P., Wang P.M. (2012): Preparation of flat-polished specimens of slag-blended cement paste for backscattered electron imaging, Advances in Cement Research, 24, 103-110. doi: 10.1680/adcr.11.00004

28. Wong H.S., Buenfeld N.R., Head M.K. (2006): Estimating transport properties of mortars using image analysis on backscattered electron images, Cement and Concrete Research, 36, 1556-1566. doi: 10.1016/j.cemconres.2006. 05.002

29. Scrivener K.L. (2004): Backscattered electron imaging of cementitious microstructures: understanding and quantification, Cement and Concrete Composites, 26, 935-945. doi: 10.1016/j.cemconcomp.2004.02.029

30. Igarashi S., Kawamura V., Watanabe A. (2004): Analysis of cement pastes and mortars by a combination of backscatterbased SEM image analysis and calculations based on the Powers model, Cement and Concrete Composites, 26, 977-985. doi:10.1016/j.cemconcomp.2004.02.031

31. Scrivener KL, Patel H, Pratt P, Parrott L. (1987): Analysis of phases in cement paste using backscattered electron images, methanol adsorption and thermogravimetric analysis. In: 
Microstructural Development During the Hydration of Cement. Proceedings of the Materials Research Society Symposium, 85, 67-76. doi: 10.1557/PROC-85-67

32. Diamond S, Leeman M. (1995): Pore size distributions in hardened cement paste by SEM image analysis. Proceedings of the Materials Research Society Symposium, 370, 217-226. doi: 10.1557/PROC-370-217

33. Diamond S., (2004): The patchy structure of cement paste in conventional concretes, International RILEM Symposium on Concrete Science and Engineering: A Tribute to Arnon Bentur, RILEM Publications, pp. 85-94.

34. Diamond S. (2006): The patch microstructure in concrete: The effect of superplasticizer, Cement and Concrete Research, 36, 776-779. doi: 10.1016/j.cemconres.2005.11. 016

35. Sanchez F., Sobolev K. (2010): Nanotechnology in concrete - A review, Construction and Building Materials, 24, 2060-2071. doi: 10.1016/j.conbuildmat.2010.03.014

36. Porro A., Dolado J.S., Gaitero J.J., Manzano H. (2010): Nanotechnology and concrete: Concepts and approach, Transportation Research Record, 2142, 127-129. doi: 10.3141/2142-19

37. Kawashima S., Seo J.W.T., Corr D., Hersam M.C., Shah S.P. (2014): Dispersion of $\mathrm{CaCO}_{3}$ nanoparticles by sonication and surfactant treatment for application in fly ash-cement systems, Materials and Structures, 47, 1011-1023. doi: 10.1617/s11527-013-0110-9
38. Diamond S. (2003): Percolation due to overlapping ITZs in laboratory mortars? A microstructural evaluation, Cement and Concrete Research, 33, 949-955. doi: 10.1016/S00088846(02)00996-1

39. Camiletti J., Soliman A.M., Nehdi M.L. (2013): Effects of nano- and micro-limestone addition on early-age properties of ultra-high-performance concrete, Materials and Structures, 46, 881-898. doi: 10.1617/s11527-012-9940-0

40. Shaikh F.U.A., Supit S.W.M. (2014): Mechanical and durability properties of high volume fly ash (HVFA) concrete containing calcium carbonate $\left(\mathrm{CaCO}_{3}\right)$ nanoparticles, Construction and Building Materials, 70, 309-321. doi: 10.1016/j.conbuildmat.2014.07.099

41. Zhang M.H., Islam J. (2012): Use of nano-silica to reduce setting time and increase early strength of concretes with high volumes of fly ash or slag, Construction and Building Materials, 29, 573-580. doi: 10.1016/j.conbuildmat.2011. 11.013

42. Kawashima S., Hou P.K., Corr D.J., Shah S.P. (2013): Modification of cement-based materials with nanoparticles, Cement and Concrete Composites, 36, 8-15. doi: 10.1016/j. cemconcomp.2012.06.012

43. Shaikh F.U.A., Supit S.W.M. (2015): Chloride induced corrosion durability of high volume fly ash concretes containing nano particles, Construction and Building Materials, 99, 208-225. doi: 10.1016/j.conbuildmat.2015. 09.030 